\title{
Parenteral immunization of mice with a genetically inactivated pertussis toxin DNA vaccine induces cell-mediated immunity and protection
}

Correspondence

Trilochan K. S. Mukkur

tk_mukkur@hotmail.com

Received 23 July 2007

Accepted 13 September 2007
Scott R. Fry, $\uparrow$ Austen Y. Chen, Grant Daggard and Trilochan K. S. Mukkur

Department of Biological and Physical Sciences, University of Southern Queensland, Toowoomba 4350, Queensland, Australia

The immunogenicity and protective efficacy of a DNA vaccine encoding a genetically inactivated $\mathrm{S} 1$ domain of pertussis toxin was evaluated using a murine respiratory challenge model of Bordetella pertussis infection. It was found that mice immunized via the intramuscular route elicited a purely cell-mediated immune response to the DNA vaccine, with high levels of gamma interferon (IFN- $\gamma$ ) and interleukin (IL)-2 detected in the S1-stimulated splenocyte supernatants and no serum IgG. Despite the lack of an antibody response, the lungs of DNA-immunized mice were cleared of $B$. pertussis at a significantly faster rate compared with mock-immunized mice following an aerosol challenge. To gauge the true potential of this S1 DNA vaccine, the immune response and protective efficacy of the commercial diphtheria-tetanus-acellular pertussis (DTaP) vaccine were included as the gold standard. Immunization with DTaP elicited a typically strong T-helper (Th)2-polarized immune response with significantly higher titres of serum lgG than in the DNA vaccine group, but a relatively weak Th1 response with low levels of IFN- $\gamma$ and IL-2 detected in the supernatants of antigen-stimulated splenocytes. DTaP-immunized mice cleared the aerosol challenge more efficiently than DNA-immunized mice, with no detectable pathogen after day 7 post-challenge.

\section{INTRODUCTION}

Bordetella pertussis, the aetiological agent of whooping cough, causes a respiratory infection of humans that is particularly severe and sometimes lethal in infants and non-immunized children. Of particular concern has been the recent upward trend in the global incidence of pertussis with a sixfold increase in reported cases over the last two decades (Cherry et al., 2005; Tan et al., 2005). Although protection can be conferred by vaccination with whole-cell pertussis $(\mathrm{wP})$ vaccines or modern acellular pertussis $(\mathrm{aP})$ vaccines, a concern with $\mathrm{wP}$ and to a lesser extent aP vaccines is their reactogenicity after multiple booster doses (Barlow et al., 2001). Systemic and local side effects, such as febrile seizures, swelling and redness around the site of injection, and encephalopathy, although rare, have been reported (Rennels et al., 2000; Gold et al., 2003; Rowe et al., 2005).

†Present address: Panbio Limited, Brisbane, Queensland, Australia.

Abbreviations: aP, acellular pertussis; $\mathrm{CHO}$, Chinese hamster ovary; $\mathrm{CMI}$, cell-mediated immunity; ConA, concanavalin A; DTaP, diphtheriatetanus-acellular pertussis; HRP, horseradish peroxidase; i.d., intradermal; IFN- $\gamma$, gamma interferon; IL, interleukin; i.m., intramuscular; IMAC, immobilized metal affinity chromatography; i.n., intranasal; i.p., intraperitoneal; PT, pertussis toxin; s.c., subcutaneous; Th, T-helper; wP, wholecell pertussis.
DNA vaccines may represent an alternative to conventional vaccines for immunization against infectious diseases such as pertussis, with the potential to induce both humoral and cell-mediated immunity (CMI). Ulmer et al. (1993) were among the first to report that a protective antigen-specific antibody and cytotoxic T-cell response could be generated in mice following immunization with DNA. Since this early finding, DNA vaccines have now been shown to be effective against a number of viral, parasitic and bacterial pathogens (Vanderzanden et al., 1998; Wang et al., 1998; Delogu et al., 2000).

Pertussis toxin (PT) is an obvious candidate for DNA vaccination against pertussis, as it is the major virulence factor of B. pertussis and, as a toxoid, is a component of all modern aP vaccines. It is a hexamer consisting of five subunits (S1, S2, S3, S4 and S5) arranged in a $1: 1: 1: 2: 1$ stoichiometry (Tamura et al., 1982), with the S1 subunit possessing ADP-ribosylating activity. Of the five subunits, S1 is the immunodominant domain (De Magistris et al., 1988). Passive immunization with S1-specific antibodies has been reported to neutralize the toxin in vitro and protect mice against aerosol or intracerebral challenge (Sato et al., 1984, 1991; Halperin et al., 1991). Systemic and mucosal humoral responses have been reported following both oral (Walker et al., 1992) and intranasal (i.n.) (Lee et al., 2003) immunization of mice with recombinant S1 
antigens. Other studies have also had success using S1derived vaccines (Boucher et al., 1994; Barry et al., 1996; Lee et al., 1999; Nascimento et al., 2000). More recently, DNA vaccines comprising the full S1 subunit (Kamachi et al., 2003) or an N-terminal fragment of S1 (Kamachi \& Arakawa, 2004, 2007) were reported to induce antibody responses when delivered by the intradermal (i.d.) route using a gene gun, and protected immunized mice against a lethal challenge.

It has been demonstrated that endogenous expression of $\mathrm{S} 1$ has a cytotoxic effect on Chinese hamster ovary $(\mathrm{CHO})$ cells (Castro et al., 2001). Therefore, an important aspect in the development of our DNA vaccine was the inactivation of the S1 gene. Pizza et al. (1989) showed that substitution of Glu-129 with Gly-129 in combination with either Arg-9 to Lys-9, Arg-13 to Leu-13 or Trp-26 to Ile-26 abolished the ADP-ribosylase activity but did not adversely affect immunogenicity. Nencioni et al. (1990) later characterized the $9 \mathrm{~K} / 129 \mathrm{G}$ toxoid and showed that it had the same physical and immunological properties as wild-type PT. For this study, we chose the $13 \mathrm{~L} / 129 \mathrm{G}$ mutation as it is reported to have marginally less leukocytosis-promoting activity and greater T-cell recognition, and mice had a higher survival rate following lethal challenge compared with the 9K/129G toxoid (Pizza et al., 1989).

As the induction of CMI is considered to be essential for immunity against pertussis (Mills et al., 1993; Mills, 2001), the aim of this study was to evaluate the potential of a parenterally delivered S1 DNA vaccine to induce both antibody and CMI, and to protect against an aerosol challenge, with a view to determining whether this mode of immunization may represent a viable alternative to $\mathrm{wP}$ and $\mathrm{aP}$ vaccines.

\section{METHODS}

Bacterial strains and growth conditions. B. pertussis strain Tohama I was used for the extraction of genomic DNA and preparation of an aerosol challenge dose. B. pertussis was grown on Bordet-Gengou (BG) agar base (Difco) with $5 \%$ defibrinated sheep blood (Oxoid) for the recovery of glycerol freezer stocks and for the determination of lung c.f.u. counts following aerosol challenge. For the preparation of suspension cultures for DNA extraction and aerosol challenge doses, the bacterium was grown in Stainer-Scholte broth supplemented with $1 \mathrm{mg}$ heptakis (2,6-O-dimethyl) $\beta$-cyclodextrin $\mathrm{ml}^{-1}$ (SSH broth) (Stainer \& Scholte, 1970; Imaizumi et al., 1983). Escherichia coli strain TOP10 (Invitrogen) was used for cloning, and E. coli XL10-Gold (Stratagene) for site-directed mutagenesis and expression of recombinant S1. E. coli strains were grown in Luria-Bertani (LB) medium (Difco) supplemented with $0.1 \mathrm{mg}$ ampicillin $\mathrm{ml}^{-1}$ (ICN) as required.

Construction of pcDNA3.1D/ptS1.13L.129G and pTrcHis2/ ptS1.13L.129G plasmids. The gene sequence encoding the $S 1$ domain of $\mathrm{PT}$, referred to as $p t S 1$, was amplified from $B$. pertussis genomic DNA by PCR using Platinum $P f x$ DNA polymerase (Invitrogen) to generate a blunt-ended product or Platinum Taq High Fidelity DNA polymerase (Invitrogen) for A-tailed products. Using the published sequence of the ptx gene (GenBank accession no.
M13223), the primers 5'-CACCATGCGTTGCACTCGGGCAATTCGC-3' and 5'-GAACGAATACGCGATGCTTTCGTAGTACAC-3' (GeneWorks) were designed to amplify from nt 507 to 1313. Genomic DNA was extracted from B. pertussis Tohama I using an AquaPure DNA isolation kit (Bio-Rad) according to the manufacturer's instructions. PCR products were cloned into the eukaryotic expression vector pcDNA3.1D/V5-His-TOPO (Invitrogen) to evaluate expression in mammalian cells in vitro and for DNA vaccination in vivo. The $p t S 1$ gene was also cloned into the prokaryotic expression vector $\mathrm{pTrcHis}$-TOPO (Invitrogen) for purification of recombinant S1. To generate this construct, the $p t S 1$ gene was amplified by PCR with the sense primer 5'-ATGCGTTGCACTCGGGCAATTCGC-3' and the antisense primer 5'-GAACGAATACGCGATGCTTTCGTAGTA-3', and ligated into the pTrcHis2-TOPO vector.

The ADP-ribosyltransferase activity of the recombinant S1 (rPTS1) encoded by $\mathrm{pTrcHis} 2 / p t s 1$ and $\mathrm{pcDNA} 3.1 / \mathrm{ptS} 1$ was inactivated by two point mutations in which Arg-13 was changed to Leu-13 and Glu-129 was changed to Gly-129 (Pizza et al., 1989). Site-directed mutagenesis was carried out using a QuikChange XL mutagenesis kit (Stratagene) according to the manufacturer's instructions. Primers used for introduction of the R13L mutation were $5^{\prime}$-TACCGCTATGACTCCCTGCCGCCGGAGGAC-3' and 5'-GAAAACGTCCTCCGGCGGCA $\overline{G G}$ GAGTCATAGCGGTA-3', and for the E129G mutation were 5'-GCCACCTACCAGAGCGGCTATCTGGCACACCGG-3' and 5'CCGGTGTGCCAGATAGCCGCTCTGGTAGGTGGC-3'.

Expression of recombinant $\mathbf{S 1}$ antigens in COS-7 cells. COS-7 cells were transfected with pcDNA3.1/ptS1, pcDNA3.1/ptS1.13L.129G or pcDNA3.1 vector (negative control) using Lipofectamine 2000 (Invitrogen) as described previously (Chen et al., 2006). Expression of rPTS1 and rPTS1.13L.129G was detected by Western blotting with an alkaline phosphatase-labelled anti-V5 antibody (Invitrogen) specific for the V5 epitope, which was fused to the $\mathrm{C}$ terminus of the recombinant S1.

CHO cell assay. To verify inactivation of rPTS1.13L.129G, a CHO cell assay was performed according to the method of Castro et al. (2001) with some modifications. CHO-K1 cells were transfected with pcDNA3.1/ptS1, pcDNA3.1/ptS1.13L or pcDNA3.1/ptS1.13L.129G using Lipofectamine 2000 as described for the transfection of COS7 cells. As a positive control, CHO-K1 cells were treated with $800 \mathrm{ng}$ commercially purified PT (List Biologicals) suspended in $0.5 \mathrm{ml}$ OptiMEM (Invitrogen). As negative controls, $\mathrm{CHO}-\mathrm{K} 1$ cells were incubated with pcDNA3.1D/ptS1, Lipofectamine 2000 or OptiMEM only. The morphology of cells in the test and control wells was recorded after $20 \mathrm{~h}$ at $37{ }^{\circ} \mathrm{C}$ with $5 \% \mathrm{CO}_{2}$, with clustering used as an indicator of intoxication.

Expression of rPTS1.13L.129G in E. coli and purification by immobilized metal affinity chromatography (IMAC). His-tagged rPTS1.13L.129G was purified by IMAC using Ni-NTA resin (Qiagen) as described previously (Chen et al., 2006). A $100 \mathrm{ml}$ culture of XL10Gold E. coli harbouring the pTrcHis2/ptS1.13L.129G plasmid was grown in LB broth to $\mathrm{OD}_{600} 0.7$ and then induced with $1 \mathrm{mM}$ IPTG for $4 \mathrm{~h}$ at $37{ }^{\circ} \mathrm{C}$ with shaking at 200 r.p.m. As a positive control, XL10-Gold E. coli transformed with the pTrcHis2/lacZ plasmid (Invitrogen), encoding $\beta$-galactosidase, was co-induced under identical conditions. Expression of rPTS1.13L.129G and $\beta$-galactosidase was detected by Western blotting with a horseradish peroxidase (HRP)-labelled anti-His-tag antibody (Invitrogen).

For purification under denaturing conditions, cells were pelleted at $12500 \mathrm{~g}$ for $5 \mathrm{~min}$, resuspended in $6 \mathrm{M}$ guanidine hydrochloride, $100 \mathrm{mM} \mathrm{NaH}{ }_{2} \mathrm{PO}_{4}, 10 \mathrm{mM}$ Tris/ $\mathrm{HCl}(\mathrm{pH} 8)$ and then incubated at room temperature for $1 \mathrm{~h}$ with shaking at 60 r.p.m. The lysate was sonicated for five cycles of $30 \mathrm{~s}$ ( $60 \%$ duty and maximum output) at $30 \mathrm{~s}$ intervals using a Branson 250 Sonifier followed by centrifugation 
at $10000 \mathrm{~g}$ for $25 \mathrm{~min}$. Ni-NTA agarose $(1 \mathrm{ml})$ was added to the clarified lysate and incubated for $40 \mathrm{~min}$ at room temperature. The slurry was loaded onto a disposable column and the matrix washed with eight bed volumes $8 \mathrm{M}$ urea, $100 \mathrm{mM} \mathrm{NaH} \mathrm{PO}_{4}, 10 \mathrm{mM}$ Tris/ $\mathrm{HCl}(\mathrm{pH} \mathrm{6.3)}$ and then eluted with two bed volumes $8 \mathrm{M}$ urea, $100 \mathrm{mM} \mathrm{NaH}{ }_{2} \mathrm{PO}_{4}, 10 \mathrm{mM}$ Tris/ $\mathrm{HCl}$ ( $\mathrm{pH}$ 5.9), followed by two bed volumes $8 \mathrm{M}$ urea, $100 \mathrm{mM} \mathrm{NaH} \mathrm{PO}_{4}, 10 \mathrm{mM}$ Tris/ $\mathrm{HCl}(\mathrm{pH} 4.5)$. The purity of rPTS1.13L.129G was checked by SDS-PAGE according to the method of Laemmli (1970) and the yield determined using a Coomassie Plus protein assay reagent (Pierce) according to the manufacturer's instructions.

Vaccination of mice. Six-week-old female $\mathrm{BALB} / \mathrm{c}$ mice were purchased from the Animal Resources Centre (Canning Vale, Western Australia). Mice were housed in a charcoal- and HEPAfiltered isolation cabinet (Techno-Plas) and fed pellet food and water ad libitum. Four groups [pcDNA3.1/ptS1.13L.129G, pcDNA3.1 vector, diphtheria-tetanus-acellular pertussis (DTaP) and a placebo] of 17 mice were given three doses at 3 week intervals. Two weeks after the final booster, five mice within each treatment group were sacrificed to determine the immunogenicity of the vaccines and controls at the time of challenge. The remaining 12 mice per group were challenged with virulent $B$. pertussis. DNA vaccine test doses consisted of $100 \mu \mathrm{g}$ plasmid DNA in $100 \mu \mathrm{l}$ PBS. Self-ligated pcDNA3.1 vector and PBS were used as negative controls and 0.2 standard human dose of the commercial DTaP vaccine (Infanrix) was included as a positive control. Each dose was administered via the intramuscular (i.m.) route with a 29 -gauge needle $(50 \mu \mathrm{g}$ injected into each quadricep) with the exception of the DTaP vaccine, which was administered via the subcutaneous (s.c.) route. Prior to i.m. or s.c. injection, mice were anaesthetised with an intraperitoneal (i.p.) dose of $80 \mathrm{mg}$ ketamine $\mathrm{kg}^{-1}$ and $16 \mathrm{mg}$ xylazine $\mathrm{kg}^{-1}$. The experiment was performed in compliance with the Animal Care and Protection Act 2001 and was approved by the Animal Ethics Committee of the University of Southern Queensland.

Analysis of serum antibody responses. The titres of anti-PT and anti-rPTS1.13L.129G IgG antibodies in mouse sera were measured by ELISA as described previously (Chen et al., 2006), with the following modifications. Nunc MaxiSorp plates were coated with $5 \mu \mathrm{g} \mathrm{PT} \mathrm{ml}{ }^{-1}$ (Seikagaku) or $5 \mu \mathrm{g}$ rPTS1.13L.129G ml ${ }^{-1}$. End-point titres were determined as the reciprocal of the highest dilution at a cut-off point 3 SD above the mean absorbance of sera from placebo-immunized mice and presented as mean titres \pm SEM. In the event that the highest dilution of test serum exceeded the cut-off value, regression was used to estimate the end-point titre.

Estimation of cytokine levels. Splenocytes from each group were pooled and resuspended in Dulbecco's modified Eagle's medium (Gibco) containing $100 \mu \mathrm{g}$ penicillin $\mathrm{ml}^{-1}, 100 \mu \mathrm{g}$ streptomycin $\mathrm{ml}^{-1}, 10 \%$ fetal bovine serum and $50 \mu \mathrm{M}$ 2-mercaptoethanol, and seeded at $5 \times 10^{6}$ cells per well. Cells were stimulated in vitro with $5 \mu \mathrm{g}$ rPTS1.13L.129G ml $\mathrm{G}^{-1}, 5 \mu \mathrm{g}$ heat-killed B. pertussis $\mathrm{ml}^{-1}$ or $2.5 \mu \mathrm{g}$ concanavalin A (ConA) $\mathrm{ml}^{-1}$. Supernatants were removed after $24 \mathrm{~h}$ incubation at $37{ }^{\circ} \mathrm{C}$ with $5 \% \mathrm{CO}_{2}$ to determine interleukin (IL)-2 production and after $72 \mathrm{~h}$ for gamma interferon (IFN- $\gamma$ ) and IL-4 measurements. The levels of the respective cytokines were determined using a mouse sandwich ELISA (Pierce) according to the manufacturer's instructions.

Aerosol challenge with B. pertussis. Mice were exposed to a sublethal infectious dose of virulent $B$. pertussis by aerosol challenge based on the method of Xing et al. (1999). B. pertussis Tohama I phase I were grown on $\mathrm{BG}$ agar for 4 days at $37^{\circ} \mathrm{C}$. Bacteria were then cultured in SSH broth at $37{ }^{\circ} \mathrm{C}$ and 150 r.p.m. until the $\mathrm{OD}_{625}$ reached 0.5 . Cells were pelleted at $2500 \mathrm{~g}$ for $10 \mathrm{~min}$ and, based on a predetermined growth curve, were resuspended to a concentration of
$1 \times 10^{10}$ c.f.u. $\mathrm{ml}^{-1}$ in $1 \%(\mathrm{w} / \mathrm{v})$ casein (Difco). Mice were exposed to aerosols from a suspension of $B$. pertussis Tohama I for $10 \mathrm{~min}$, which was previously determined to deliver a sublethal infectious dose of $5.7 \times 10^{5}( \pm 0.1)$ c.f.u. per lung. Four mice per group were sacrificed at days 4,7 and 14 post-challenge to determine the number of $B$. pertussis in the lungs. Lungs were removed aseptically and homogenized in $1 \mathrm{ml} 1 \%$ casein on ice. Serial dilutions of each homogenate were spotted in quadruplicate onto BG agar and incubated at $37{ }^{\circ} \mathrm{C}$ for 4 days. Bacterial counts were expressed as mean c.f.u. per lung \pm SEM.

Statistical analysis of data. Significant differences in antibody titres and clearance data were identified using a paired $t$-test or analysis of variance for multiple comparisons. Differences between groups were considered significant if $P \leqslant 0.05$.

\section{RESULTS AND DISCUSSION}

\section{Expression and purification of rPTS1.13L.129G}

IPTG-induced expression of the rPTS1.13L.129G fusion protein was detected in the lysate of transformed E. coli by Western blotting using an HRP-labelled anti-His-tag antibody (Fig. 1a). A dominant band of $30 \mathrm{kDa}$ was observed and corresponded well to the calculated molecular mass of rPTS1.13L.129G, as determined from the amino acid sequence (VectorNTI; Invitrogen). When constitutively expressed in COS-7 cells following transfection with pcDNA3.1D/pts1.13L.129G, rPTS1.13L.129G had a molecular mass that was equivalent to rPTS1.13L.129G expressed and purified from E. coli (Fig. 1b). Following expression in the mammalian cell line COS-7,

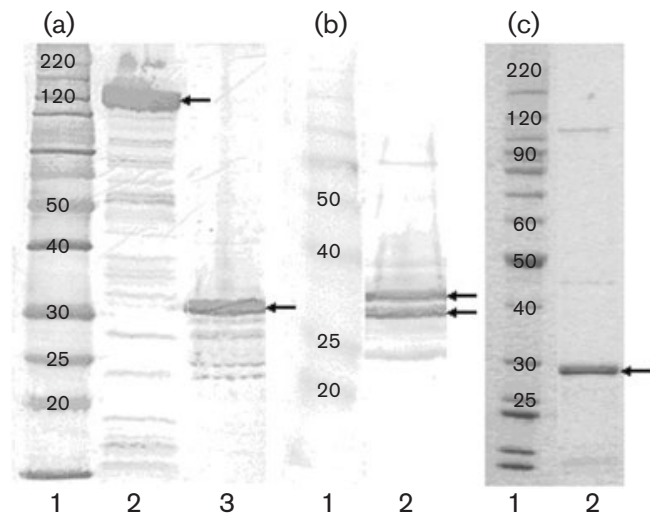

Fig. 1. Expression and purification of rPTS1.13L.129G. (a) IPTGinduced expression of $\beta$-galactosidase (positive control, lane 2) and rPTS1.13L.129G (lane 3) in E. coli was detected by Western blot using an HRP-labelled anti-His-tag antibody. (b) Constitutively expressed rPTS1.13L.129G in mammalian COS-7 cells was detected by Western blot using an alkaline phosphatase-labelled anti-V5 tag antibody. (c) SDS-PAGE of rPTS1.13L.129G purified from an $E$. coli lysate under denaturing conditions by IMAC (lane 2). Arrows indicate rPTS1.13L.129G. 1, Molecular mass markers [BenchMark protein ladder (Invitrogen) $(\mathrm{a}, \mathrm{c})$ or pre-stained Benchmark protein ladder (Invitrogen) (b)]. 
rPTS1.13L.129G appeared as a doublet, indicating that there were two isoforms of the recombinant protein, which are likely to have occurred through atypical posttranslational modification. The level of rPTS1.13L.129G expression in XL10-Gold E. coli was found to be sufficient for purification by IMAC (Fig. 1c).

\section{Cytotoxicity of rPTS1.13L.129G}

A $\mathrm{CHO}$ cell assay was used to determine the relative toxicity of the mutant rPTS1.13L.129G and rPTS1.13L analogues compared with the non-mutated $\mathrm{rS} 1$ and native PT. Unlike untreated cells, which grew as a confluent monolayer (Fig. 2e, f), CHO-K1 cells transfected with $\mathrm{pcDNA3.1D/ptS1}$ (endogenous expression of the nonmutated rPTS1 protein) developed a clustered appearance within $12 \mathrm{~h}$ (Fig. 2a). This clustered morphology was also observed for the cells treated with wild-type PT (Fig. 2d). Overall, the clustering appeared to be slightly more pronounced and compact in the PT treatment group compared with cells transfected with pcDNA3.1D/ptS1. Endogenous expression of rPTS1.13L.129G following transfection of $\mathrm{CHO}$ cells with pcDNA3.1D/ ptS1.13L.129G had little or no effect on the cell morphology (Fig. 2c) and the cells were similar in appearance to untreated cells. The cumulative effect of two point mutations versus a single amino acid substitution was tested by including a group of $\mathrm{CHO}$ cells transfected with pcDNA3.1D/ptS1.13L for the endogenous expression of rPTS1.13L (Fig. 2b). Whilst there appeared to be a low level of clustering that was not present in the pcDNA3.1D/
ptS1.13L.129G treatment group, the clustering was less obvious than with cells transfected with pcDNA3.1D/ptS1 (endogenous expression of rPTS1) or treated with native PT. Castro et al. (2001) also observed clustering in $\mathrm{CHO}$ cells that expressed the wild-type $\mathrm{S} 1$ and a normal $\mathrm{CHO}$ cell morphology after endogenous expression of a 9K/129G mutant. The results of our modified $\mathrm{CHO}$ cell assay were consistent with those of Castro et al. (2001) as rPTS1.13L.129G had no apparent ADP-ribosylase activity but cells transfected with the non-mutated S1 construct (pcDNA3.1D/pts1) showed a rounded and clustered morphology that was comparable with exposure of cells to native PT.

\section{Cytokine levels produced by splenocytes of immunized mice}

Splenocytes of mice immunized with pcDNA3.1D/ ptS1.13L.129G produced high levels of IFN- $\gamma$ when cultured in the presence of either rPTS1.13L.129G or ConA, with 5253 and $6000 \mathrm{pg} \mathrm{ml}^{-1}$, respectively (Fig. 3). When stimulated with a heat-killed $B$. pertussis lysate, these cells produced less IFN- $\gamma\left(1629 \mathrm{pg} \mathrm{ml}^{-1}\right)$. Splenocytes from vector- and DTaP-immunized mice produced a low level of IFN- $\gamma$ when stimulated with rPTS1.13L.129G or the B. pertussis lysate (Fig. 3). Splenocytes from mice immunized with pcDNA3.1D/ptS1.13L.129G, vector and the $\mathrm{DTaP}$ vaccine all produced low levels of IL-2 when stimulated with rPTS1.13L.129G (Fig. 4). Moreover, there was virtually no IL-2 detected when the splenocytes from mice immunized with pcDNA3.1D/ptS1.13L.129G were
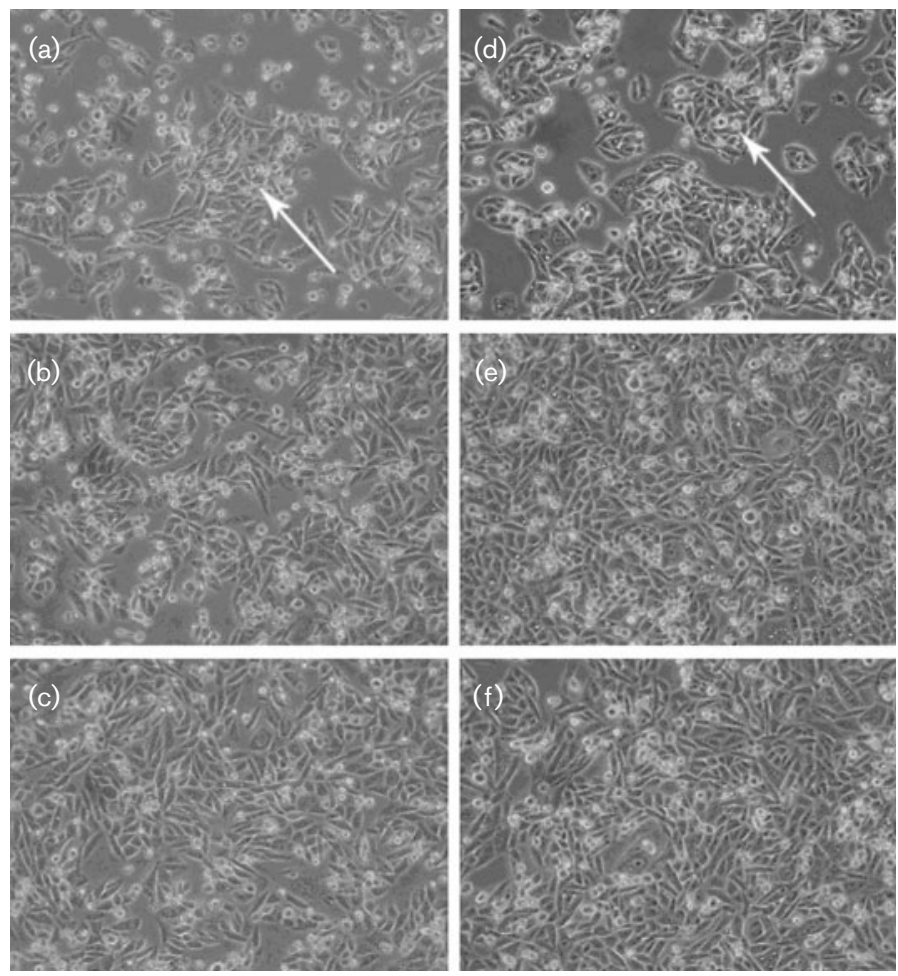

Fig. 2. $\mathrm{CHO}-\mathrm{K} 1$ cell morphology following exposure to rPTS1, rPTS1.13L and rPTS1.13L.129G antigens. A representative section of adherent cells was recorded $20 \mathrm{~h}$ after transfection with $2.5 \mu \mathrm{g}$ pcDNA3.1D/ ptS1 (endogenous expression of rPTS1) (a), transfection with $2.5 \mu \mathrm{g}$ pcDNA3.1D/ ptS1.13L (rPTS1.13L) (b), transfection with $2.5 \mu \mathrm{g}$ pcDNA3.1D/ptS1.13L.129G (rPTS1.13L.129G) (c), treatment with $800 \mathrm{ng}$ PT (List Biologicals) (d), addition of Lipofectamine 2000 without plasmid DNA (untreated) (e) and addition of pcDNA3.1D/ptS1 plasmid DNA without Lipofectamine 2000 (untreated) (f). Arrows indicate the clustered morphology of $\mathrm{CHO}-\mathrm{K} 1$. Magnification $\times 200$. 


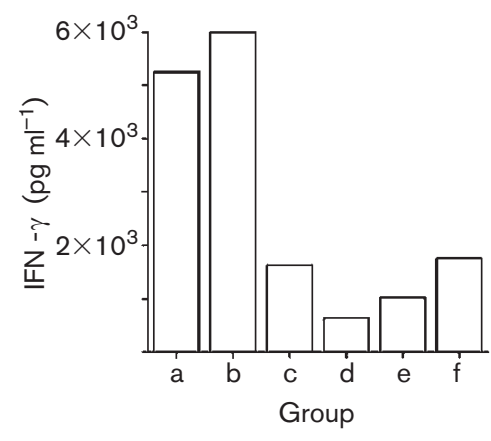

Fig. 3. IFN- $\gamma$ production from splenocytes stimulated with rS1.13L.129G. Results are shown for splenocytes from pcDNA3.1D/ptS1.13L.129G-immunized mice stimulated with $5 \mu \mathrm{g}$ rPTS1.13L.129G ml ${ }^{-1}$ (a), $2.5 \mu \mathrm{g} \mathrm{ConA} \mathrm{ml}^{-1}$ (b) or $5 \mu \mathrm{g}$ heat-killed B. pertussis $\mathrm{ml}^{-1}$ (c), and for splenocytes from vector-immunized mice stimulated with $5 \mu \mathrm{g}$ rPTS1.13L.129G ml ${ }^{-1}$ (d) or $5 \mu \mathrm{g}$ heatkilled $B$. pertussis $\mathrm{ml}^{-1}(\mathrm{e})$, and for splenocytes from DTaPimmunized mice stimulated with $5 \mu \mathrm{g}$ rPTS1.13L.129G $\mathrm{ml}^{-1}$ (f). Data was obtained from a pooled splenocyte population from a single experiment.

stimulated with a heat-killed $B$. pertussis lysate. In contrast, a large amount of IL-2 (12.3 $\left.\mathrm{ng} \mathrm{ml}^{-1}\right)$ was produced when these same cells were stimulated with ConA (Fig. 4). In mice vaccinated with pcDNA3.1D/ptS1.13L.129G, there was little IL-4 produced when stimulated with rPTS1.13L.129G (15.3 $\mathrm{pg} \mathrm{ml}^{-1}$ ); in contrast, there was a relatively large amount of IL-4 produced by these splenocytes following stimulation with ConA (468.2 pg $\mathrm{ml}^{-1}$ ) (data not shown). Mice vaccinated with pcDNA3.1D

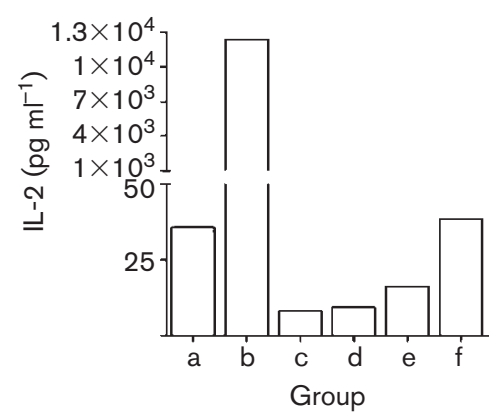

Fig. 4. IL-2 production from rPTS1.13L.129G-stimulated splenocytes. Results are shown for splenocytes from pcDNA3.1D/ ptS1.13L.129G-immunized mice stimulated with $5 \mu \mathrm{g}$ rPTS1.13L.129G ml ${ }^{-1}$ (a), $2.5 \mu \mathrm{g} \mathrm{ConA} \mathrm{ml}^{-1}$ (b) or $5 \mu \mathrm{g}$ heat-killed $B$. pertussis $\mathrm{ml}^{-1}$ (c), and for splenocytes from vector-immunized mice stimulated with $5 \mu \mathrm{g}$ rPTS1.13L.129G ml ${ }^{-1}$ (d) or $5 \mu \mathrm{g}$ heatkilled $B$. pertussis $\mathrm{ml}^{-1}$ (e), and for splenocytes from DTaPimmunized mice stimulated with $5 \mu \mathrm{g} \mathrm{rPTS} 1.13 \mathrm{~L} .129 \mathrm{G} \mathrm{ml}^{-1}$ (f). vector produced equivalent levels of IL-4 to mice given the DNA vaccine $\left(12.8 \mathrm{pg} \mathrm{ml}^{-1}\right)$.

\section{IgG titres in the serum of immunized mice}

No serum IgG against the rPTS1.13L.129G fusion protein or native PT was detected in mice vaccinated with pcDNA3.1D/ptS1.13L.129G or pcDNA3.1D vector only. In contrast, mice vaccinated with the DTaP vaccine showed a high degree of seroconversion, with IgG ELISA titres of $14080( \pm 9380)$ and $92369( \pm 17753)$ detected against rPTS1 and native PT, respectively. Further analysis of serum samples from mice immunized with DTaP showed that the majority of IgG elicited was of the IgG1 subclass with an IgG1 to IgG2a ratio of $150: 1$. The T-helper (Th)2biased response we observed following immunization with DTaP is consistent with other studies, which have shown that mice elicit protective IgG responses following immunization with aP vaccines (Redhead et al., 1993; van den Berg et al., 2000). It is important to note that, although i.m. injection is the recommended route of administration of DTaP in humans, the route used in the mouse model has typically been a series of i.p. or s.c. injections rather than the i.m. route (Redhead et al., 1993; Barnard et al., 1996; Mahon et al., 1996; McGuirk \& Mills, 2000; van den Berg et al., 2000; Donnelly et al., 2001). Although the reason for this deviation from the human mode of delivery has not been highlighted, these studies have demonstrated that the protective IgG response to aP vaccines following i.p. or s.c. administration in mice appears to correlate well with the response to i.m. immunization of DTaP in humans (Greco et al., 1996; Gustafsson et al., 1996; Olin et al., 1997). Our rationale for choosing the s.c. route of administration was based on studies investigating the efficacy of aP vaccines in mice, which delivered $0.2-0.25$ standard human dose of vaccine via the s.c. route (Barnard et al., 1996; van den Berg et al., 2000; Donnelly et al., 2001). It may be interesting to compare the immune response of mice in which the DNA vaccine is also administered via the s.c. route with alum as an adjuvant or in which the DTaP vaccine is administered via the i.m. route, as is used in human immunization.

Based on both human and animal studies of immunity against $B$. pertussis, PT-neutralizing IgG1 antibodies are believed to be an important protective mechanism (Sato et al., 1984; Halperin et al., 1991; Schneerson et al., 1996), albeit in the early phases of infection. Kamachi et al. (2003) reported that i.d. immunization of mice with an S1 DNA vaccine generated significant IgG1 titres that protected against both the toxic effects of PT and a lethal i.n. challenge with virulent $B$. pertussis. In our investigation involving DNA vaccination by the i.m. route, no IgG could be detected. It was thus apparent that unless strategies to induce a Th2-mediated humoral immune response, for example by simultaneous immunization with the DNA vaccine by both the i.m. and i.d. routes or the coadministration of purified antigen, are investigated, the 
lack of toxin-neutralizing $\operatorname{IgG}$ in the serum would be a limitation of this vaccine.

\section{Protective efficacy of pcDNA3.1/ptS1.13L.129G injected via the i.m. route}

As a measure of protective efficacy, bacterial numbers from the lungs of challenged mice were recorded at days 4, 7 and 14 post-challenge. The results of the challenge experiment showed that mice immunized with pcDNA3.1D/ ptS1.13L.129G cleared the B. pertussis infection more effectively than mice given the placebo or vector only, but not when compared with the DTaP vaccine, which cleared the infection at a significantly faster rate than the DNA vaccine (Fig. 5). At day 4 post-challenge, mice vaccinated with either pcDNA3.1D/ptS1.13L.129G, the placebo or vector only showed a twofold to fourfold increase in bacterial numbers compared with day 0 counts. By day 7, the DNA-vaccinated mice showed a 10 -fold reduction in numbers followed by a more than 6000 -fold reduction after 2 weeks, whereas the negative-control mice failed to show any reduction in the c.f.u. counts. The clearance data showed that bacterial counts in mice immunized with pcDNA3.1D/ptS1.13L.129G were reduced to $1.46 \%$ of the placebo controls at day 7 post-challenge and then to $0.001 \%$ at day 14 post-challenge. Three of the four mice immunized with the DNA vaccine failed to clear the $B$. pertussis infection completely within 14 days of challenge. In contrast, mice immunized with the DTaP vaccine demonstrated a more rapid and complete clearance with no bacteria detected in the lungs at day 7 postchallenge, with a significantly improved rate of clearance

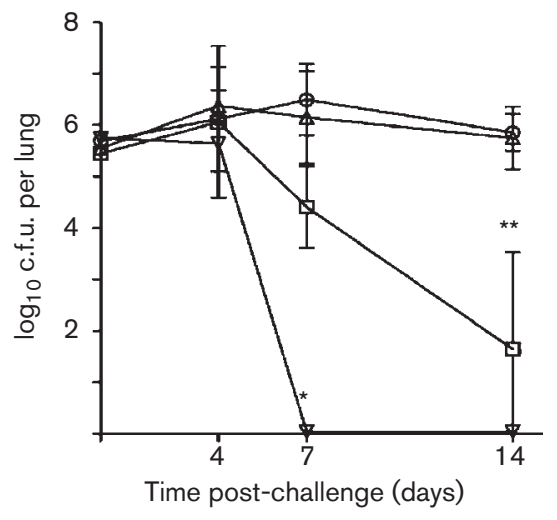

Fig. 5. Bacterial loads in the lungs of pcDNA3.1D/ ptS1.13L.129G-vaccinated mice and controls following a sublethal aerosol challenge with virulent $B$. pertussis Tohama I. Data points represent mean c.f.u. \pm SEM from four mice. *, Significantly different from pcDNA3.1D/ptS1.13L.129G, pcDNA3.1D vector and placebo $(P<0.05) ;{ }^{* *}$, significantly different from pcDNA3.1D vector and placebo $(P<0.05)$. $\square$, pcDNA3.1D/ptS1.13L.129G; $\triangle$, pcDNA3.1D; $\bigcirc$, placebo; $\nabla, \mathrm{DTaP}$. compared with mice given the DNA vaccine, vector only or placebo $(P<0.05)$ (Fig. 5).

It has been reported that immunization of mice by the i.d. route using a gene gun with a pcDNA/S1 DNA vaccine induced a significant IgG1 response that protected against the toxic effects of PT, as well as a lethal i.n. challenge with virulent B. pertussis (Kamachi et al., 2003). More recently, it was reported that the region encoding the $\mathrm{N}$-terminal 180 aa fragment of the S1 subunit could also induce a protective immune response (Kamachi \& Arakawa, 2004, 2007). In the present study, we investigated whether DNA vaccination with a genetically inactivated $S 1$ subunit via the i.m. route could confer protection against an aerosol challenge. DNA vaccination of mice with the pcDNA3.1D/ ptS1.13L.129G plasmid induced a potent CMI response as indicated by a high level of IFN- $\gamma$ produced from splenocytes restimulated with rPTS1.13L.129G. In fact, levels of this cytokine approached that following stimulation with ConA, a natural and potent T-cell mitogen. No IgG to rPTS1.13L.129G or native PT could be detected in the sera of mice immunized with our parenteral S1 DNA vaccine. Although there has been relatively little insight into the mechanisms of DNA uptake and processing of endogenously expressed antigen, it has become apparent that the mode of delivery of DNA vaccines is a major influence on whether a humoral or cellular response is generated. Most DNA vaccines administered via the i.m. route have induced a Th1-biased response, whereas DNA delivered via the i.d. route by gene gun typically directs a Th2-type response (Donnelly et al., 1997; Klinman et al., 1997; Gurunathan et al., 2000).

Interestingly, Redhead et al. (1993) found that although high serum antibody levels resulted in an earlier decline in the numbers of $B$. pertussis recovered from the lungs of challenged mice, complete clearance was dependent on CMI. Also, the dichotomous albeit slightly Th1-biased response to $\mathrm{wP}$ vaccines has been shown to produce a greater reduction in bacteria compared with the purely Th2 response induced by acellular vaccines (Mills et al., 1998). From the results of this study, we believe that a composite vaccine, in which purified toxoid is either co-administered or used as a booster for DNA vaccination, may be more efficacious against $B$. pertussis than immunization with purified antigen or DNA alone. It will be interesting to determine whether immunization with a combination DNA$\mathrm{aP}$ vaccine will generate both antibody and $\mathrm{CMI}$ responses and protect mice against challenge with $B$. pertussis.

In conclusion, we have shown that DNA vaccination of mice with the S1 subunit of PT can enhance the rate of clearance of a $B$. pertussis infection through the induction of a Th1 immune response. Although the S1 DNA vaccine was not as efficacious in clearing the aerosol challenge as the $\mathrm{DTaP}$ vaccine, the result was nevertheless encouraging considering it involved the coverage of only one of the virulence antigens of $B$. pertussis and the absence of any adjuvant. 


\section{ACKNOWLEDGEMENTS}

We wish to thank Scott Kershaw and Youhong $\mathrm{Xu}$ for technical assistance, Peter Dunn for advice on statistical analysis of the data, Oliver Kinder for the design and building of the aerosol challenge chamber and GlaxoSmithKline Australia for kindly donating the DTaP vaccine. This work was supported by Delta Biotechnology Ltd (Australia) and an internal research grant awarded by the University of Southern Queensland to T. K. S. M.

\section{REFERENCES}

Barlow, W. E., Davis, R. L., Glasser, J. W., Rhodes, P. H., Thompson, R. S., Mullooly, J. P., Black, S. B., Shinefield, H. R., Ward, J. I. \& other authors (2001). The risk of seizures after receipt of whole-cell pertussis or measles, mumps, and rubella vaccine. N Engl J Med 345, 656-661.

Barnard, A., Mahon, B. P., Watkins, J., Redhead, K. \& Mills, K. H. (1996). Th1/Th2 cell dichotomy in acquired immunity to Bordetella pertussis: variables in the in vivo priming and in vitro cytokine detection techniques affect the classification of T-cell subsets as Th1, Th2 or Th0. Immunology 87, 372-380.

Barry, E. M., Gomez-Duarte, O., Chatfield, S., Rappuoli, R., Pizza, M., Losonsky, G., Galen, J. \& Levine, M. M. (1996). Expression and immunogenicity of pertussis toxin S1 subunit-tetanus toxin fragment C fusions in Salmonella typhi vaccine strain CVD 908. Infect Immun 64, 4172-4181.

Boucher, P., Sato, H., Sato, Y. \& Locht, C. (1994). Neutralizing antibodies and immunoprotection against pertussis and tetanus obtained by use of a recombinant pertussis toxin-tetanus toxin fusion protein. Infect Immun 62, 449-456.

Castro, M. G., McNamara, U. \& Carbonetti, N. H. (2001). Expression, activity and cytotoxicity of pertussis toxin $\mathrm{S} 1$ subunit in transfected mammalian cells. Cell Microbiol 3, 45-54.

Chen, A. Y., Fry, S. R., Forbes-Faulkner, J., Daggard, G. E. \& Mukkur, T. K. (2006). Comparative immunogenicity of M. hyopneumoniae $\mathrm{NrdF}$ encoded in different expression systems delivered orally via attenuated S. typhimurium aroA in mice. Vet Microbiol 114, 252-259.

Cherry, J. D., Grimprel, E., Guiso, N., Heininger, U. \& Mertsola, J. (2005). Defining pertussis epidemiology: clinical, microbiologic and serologic perspectives. Pediatr Infect Dis J 24 (Suppl.), S25-S34.

De Magistris, M. T., Romano, M., Nuti, S., Rappuoli, R. \& Tagliabue, A. (1988). Dissecting human $T$ cell responses against Bordetella species. J Exp Med 168, 1351-1362.

Delogu, G., Howard, A., Collins, F. M. \& Morris, S. L. (2000). DNA vaccination against tuberculosis: expression of a ubiquitin-conjugated tuberculosis protein enhances antimycobacterial immunity. Infect Immun 68, 3097-3102.

Donnelly, J. J., Ulmer, J. B., Shiver, J. W. \& Liu, M. A. (1997). DNA vaccines. Annu Rev Immunol 15, 617-648.

Donnelly, S., Loscher, C. E., Lynch, M. A. \& Mills, K. H. (2001). Wholecell but not acellular pertussis vaccines induce convulsive activity in mice: evidence of a role for toxin-induced interleukin- $1 \beta$ in a new murine model for analysis of neuronal side effects of vaccination. Infect Immun 69, 4217-4223.

Gold, M. S., Noonan, S., Osbourn, M., Precepa, S. \& Kempe, A. E. (2003). Local reactions after the fourth dose of acellular pertussis vaccine in South Australia. Med J Aust 179, 191-194.

Greco, D., Salmaso, S., Mastrantonio, P., Giuliano, M., Tozzi, A. E., Anemona, A., Ciofi degli Atti, M. L., Giammanco, A., Panei, P. \& other authors (1996). A controlled trial of two acellular vaccines and one whole-cell vaccine against pertussis. $N$ Engl J Med 334, 341-349.
Gurunathan, S., Klinman, D. M. \& Seder, R. A. (2000). DNA vaccines: immunology, application, and optimization. Annu Rev Immunol 18, 927-974.

Gustafsson, L., Hallander, H. O., Olin, P., Reizenstein, E. \& Storsaeter, J. (1996). A controlled trial of a two-component acellular, a five-component acellular, and a whole-cell pertussis vaccine. $N$ Engl J Med 334, 349-355.

Halperin, S. A., Issekutz, T. B. \& Kasina, A. (1991). Modulation of Bordetella pertussis infection with monoclonal antibodies to pertussis toxin. J Infect Dis 163, 355-361.

Imaizumi, A., Suzuki, Y., Ono, S., Sato, H. \& Sato, Y. (1983). Heptakis(2,6-O-dimethyl) $\beta$-cyclodextrin: a novel growth stimulant for Bordetella pertussis phase I. J Clin Microbiol 17, 781-786.

Kamachi, K. \& Arakawa, Y. (2004). Expression of a C terminally truncated form of pertussis toxin $\mathrm{S} 1$ subunit effectively induces protection against pertussis toxin following DNA-based immunization. Infect Immun 72, 4293-4296.

Kamachi, K. \& Arakawa, Y. (2007). Development of safer pertussis DNA vaccine expressing non-toxic C180 polypeptide of pertussis toxin S1 subunit. Vaccine 25, 1000-1006.

Kamachi, K., Konda, T. \& Arakawa, Y. (2003). DNA vaccine encoding pertussis toxin $\mathrm{S} 1$ subunit induces protection against Bordetella pertussis in mice. Vaccine 21, 4609-4615.

Klinman, D. M., Yamshchikov, G. \& Ishigatsubo, Y. (1997). Contribution of $\mathrm{CpG}$ motifs to the immunogenicity of DNA vaccines. J Immunol 158, 3635-3639.

Laemmli, U. K. (1970). Cleavage of structural proteins during the assembly of the head of bacteriophage T4. Nature 227, 680-685.

Lee, S. F., March, R. J., Halperin, S. A., Faulkner, G. \& Gao, L. (1999). Surface expression of a protective recombinant pertussis toxin S1 subunit fragment in Streptococcus gordonii. Infect Immun 67, 1511-1516.

Lee, S. F., Halperin, S. A., Salloum, D. F., MacMillan, A. \& Morris, A. (2003). Mucosal immunization with a genetically engineered pertussis toxin S1 fragment-cholera toxin subunit B chimeric protein. Infect Immun 71, 2272-2275.

Mahon, B. P., Ryan, M. S., Griffin, F. \& Mills, K. H. (1996). Interleukin12 is produced by macrophages in response to live or killed Bordetella pertussis and enhances the efficacy of an acellular pertussis vaccine by promoting induction of Th1 cells. Infect Immun 64, 5295-5301.

McGuirk, P. \& Mills, K. H. G. (2000). A regulatory role for interleukin 4 in differential inflammatory response in the lung following infection of mice primed with Th1- or Th2-inducing pertussis vaccines. Infect Immun 68, 1383-1390.

Mills, K. H. (2001). Immunity to Bordetella pertussis. Microbes Infect $\mathbf{3}$, 655-677.

Mills, K. H., Barnard, A., Watkins, J. \& Redhead, K. (1993). Cellmediated immunity to Bordetella pertussis: role of Th1 cells in bacterial clearance in a murine respiratory infection model. Infect Immun 61, 399-410.

Mills, K. H., Ryan, M., Ryan, E. \& Mahon, B. P. (1998). A murine model in which protection correlates with pertussis vaccine efficacy in children reveals complementary roles for humoral and cell-mediated immunity in protection against Bordetella pertussis. Infect Immun 66, 594-602.

Nascimento, I. P., Dias, W. O., Mazzantini, R. P., Miyaji, E. N., Gamberini, M., Quintilio, W., Gebara, V. C., Cardoso, D. F., Ho, P. L. \& other authors (2000). Recombinant Mycobacterium bovis BCG expressing pertussis toxin subunit $\mathrm{S} 1$ induces protection against an intracerebral challenge with live Bordetella pertussis in mice. Infect Immun 68, 4877-4883. 
Nencioni, L., Pizza, M., Bugnoli, M., De Magistris, T., Di Tommaso, A., Giovannoni, F., Manetti, R., Marsili, I., Matteucci, G. \& other authors (1990). Characterization of genetically inactivated pertussis toxin mutants: candidates for a new vaccine against whooping cough. Infect Immun 58, 1308-1315.

Olin, P., Rasmussen, F., Gustafsson, L., Hallander, H. O., Heijbel, H. \& for the Ad Hoc Group for the Study of Pertussis Vaccines (1997). Randomised controlled trial of two-component, three-component, and five-component acellular pertussis vaccines compared with whole-cell pertussis vaccine. Lancet 350, 1569-1577.

Pizza, M., Covacci, A., Bartoloni, A., Perugini, M., Nencioni, L., De Magistris, M. T., Villa, L., Nucci, D., Manetti, R. \& other authors (1989). Mutants of pertussis toxin suitable for vaccine development. Science 246, 497-500.

Redhead, K., Watkins, J., Barnard, A. \& Mills, K. H. (1993). Effective immunization against Bordetella pertussis respiratory infection in mice is dependent on induction of cell-mediated immunity. Infect Immun 61, 3190-3198.

Rennels, M. B., Deloria, M. A., Pichichero, M. E., Losonsky, G. A., Englund, J. A., Meade, B. D., Anderson, E. L., Steinhoff, M. C. \& Edwards, K. M. (2000). Extensive swelling after booster doses of acellular pertussis-tetanus-diphtheria vaccines. Pediatrics 105, e12.

Rowe, J., Yerkovich, S. T., Richmond, P., Suriyaarachchi, D., Fisher, E., Feddema, L., Loh, R., Sly, P. D. \& Holt, P. G. (2005). Th2-associated local reactions to the acellular diphtheria-tetanus-pertussis vaccine in 4- to 6-year-old children. Infect Immun 73, 8130-8135.

Sato, Y., Kimura, M. \& Fukumi, H. (1984). Development of a pertussis component vaccine in Japan. Lancet 1, 122-126.

Sato, H., Sato, Y. \& Ohishi, I. (1991). Comparison of pertussis toxin (PT)-neutralizing activities and mouse-protective activities of anti-PT mouse monoclonal antibodies. Infect Immun 59, 3832-3835.

Schneerson, R., Robbins, J. B., Taranger, J., Lagergard, T. \& Trollfors, B. (1996). A toxoid vaccine for pertussis as well as diphtheria? Lessons to be relearned. Lancet 348, 1289-1292.
Stainer, D. W. \& Scholte, M. J. (1970). A simple chemically defined medium for the production of phase I Bordetella pertussis. J Gen Microbiol 63, 211-220.

Tamura, M., Nogimori, K., Murai, S., Yajima, M., Ito, K., Katada, T., Ui, M. \& Ishii, S. (1982). Subunit structure of islet-activating protein, pertussis toxin, in conformity with the A-B model. Biochemistry 21, $5516-5522$.

Tan, T., Trindade, E. \& Skowronski, D. (2005). Epidemiology of pertussis. Pediatr Infect Dis J 24 (Suppl.), S10-S18.

Ulmer, J. B., Donnelly, J. J., Parker, S. E., Rhodes, G. H., Felgner, P. L., Dwarki, V. J., Gromkowski, S. H., Deck, R. R., DeWitt, C. M. \& other authors (1993). Heterologous protection against influenza by injection of DNA encoding a viral protein. Science 259, 1745-1749.

van den Berg, B. M., David, S., Beekhuizen, H., Mooi, F. R. \& van Furth, R. (2000). Protection and humoral immune responses against Bordetella pertussis infection in mice immunized with acellular or cellular pertussis immunogens. Vaccine 19, 1118-1128.

Vanderzanden, L., Bray, M., Fuller, D., Roberts, T., Custer, D., Spik, K., Jahrling, P., Huggins, J., Schmaljohn, A. \& Schmaljohn, C. (1998). DNA vaccines expressing either the GP or NP genes of Ebola virus protect mice from lethal challenge. Virology 246, 134-144.

Walker, M. J., Rohde, M., Timmis, K. N. \& Guzman, C. A. (1992). Specific lung mucosal and systemic immune responses after oral immunization of mice with Salmonella typhimurium aroA, Salmonella typhi Ty21a, and invasive Escherichia coli expressing recombinant pertussis toxin S1 subunit. Infect Immun 60, 4260-4268.

Wang, R., Doolan, D. L., Le, T. P., Hedstrom, R. C., Coonan, K. M., Charoenvit, Y., Jones, T. R., Hobart, P., Margalith, M. \& other authors (1998). Induction of antigen-specific cytotoxic $T$ lymphocytes in humans by a malaria DNA vaccine. Science 282 , 476-480.

Xing, D. K., Das, R. G., Williams, L., Canthaboo, C., Tremmil, J. \& Corbel, M. J. (1999). An aerosol challenge model of Bordetella pertussis infection as a potential bioassay for acellular pertussis vaccines. Vaccine 17, 565-576. 